\title{
EL DERECHO DE RESISTENCIA EN LA MODERNIDAD OTOÑAL
}

[The Right to Resistance in the Late Modern Times]

\author{
Francisco Carpintero Benítez* \\ Universidad de Cádiz, España
}

\section{RESUMEN}

El pensamiento aristotélico en Europa desde el Siglo 13, el contractualismo político jurídico ganó terreno. La Idea de contrato implica que la otra parte queda liberada de sus compromisos y este requisito, en el área de la política, comprende recurrir a la violencia moral o física. En segundo lugar, los teólogos y juristas españoles escolásticos aludieron con firmeza a este requisito contractual: pero sus teorías se perdieron a medida que avanzaba la época moderna. La teoría monárquica culminó en el siglo XVIII, y el autor estudia los trabajos de los principales abogados de este siglo en relación a sus actitudes ante la aplicación injusta del poder. Estos autores fueron irrelevantes porque a pesar de haber

\begin{abstract}
The Since ranged Aristotelian thought in Europe, from the $13^{\text {th }}$ century, the political-juridical contractualism won ground. The idea of the contract determines that the other party is released from their commitments and this requirement, in the area of politics, involves recourse to moral or physical violence. Second Scholasticism Spanish theologians and Jurists pointed out vigorously this contractual requirement; but his theories were lost as it advanced the modern age. Monarchist theory reaches its culmination in the 18th century, and the author examines the works of leading lawyers of this century to observe their attitude before the power acting unjustly. These authors were inconsequential because
\end{abstract}

Recibido el 8 de agosto de 2017 y ACEPTADO el 13 de junio de 2018

* Catedrático emérito de filosofía del derecho de la Universidad de Cádiz, España. Dirección electrónica: francisco.carpintero@ucs.es 
recalcado el origen contractual del poder rechazaron el derecho de resistencia contra la injusticia. Solo Daniel Nettelbladt parece haber atenuado este derecho de las gentes o populus.

\section{Palabras Clave}

Derecho de resistencia - Tiranía Rebelión - Insurgencia. they emphasized the contractual origin of power but they refused the right of resistance against injustice; only Daniel Nettelbladt seemed to have in has diluted this right of the people or populus.

KEYwORDS
Right of resistance - Tyranny -
Rebellion - Insurgency.

Hay estudios hechos en español sobre el derecho de resistencia del pueblo frente al gobernante que gobernaba despóticamente en el siglo XVII ${ }^{1}$, y para hacer honor a la historia es procedente ocuparse de la totalidad de la Modernidad. El siglo XVIII es un momento en el que la Escuela del Derecho Natural es más jurisprudencial que en el momento anterior: juristas como Daries, Nettelbladt, Heineccius o Burlamachi componen tratados de derecho más o menos completos, quizá con vistas a ser recogidos en las codificaciones que ya habían comenzado: un proceso largo, el de la codificación, que desde los tiempos de Samuel Cocceius hasta la aparición del Allgemeines Landrecht prusiano tardó casi un siglo en madurar.

Las grandes polémicas del siglo anterior habían pasado y se había impuesto un pensamiento bastante uniforme que responde al que es propio de esta Escuela. Hablo de uniformidad porque tienen en cuenta todos cuatro puntos de partida: los individuos aislados y libres que buscan integrarse en una sociedad. Una concepción del derecho que sea suficientemente subjetiva. La formación de las leyes fundamentales en la constitución de la sociedad y esta constitución misma hecha mediante un contrato. Nadie que aspirara a ser leído o escuchado en clase o en los salones podía escapar de este cuadro normativo. Los 'derechos del hombre' solamente eran inteligibles desde estas bases anteriores. Y también hay un sentimiento soterrado que lo explicita Heineccius ${ }^{2}$. No a la obedientiam passivam de Hobbes y de otros ingleses: Haec principia omnia non minus pestilentia esse, ac monarchomachorum dogmata, nemo temere negaverit, "Porque estos principios [los de Hobbes] no son menos pestilentes que los dogmas de los monarcómacos, a los que nadie puede tener miedo a negar".

Ciertamente, la mayor parte de los teóricos ilustrados no era conscientes - ni remotamente- de sus orígenes medievales y escolásticos los escolásticos de los siglos XVIII y XX tampoco conocían sus orígenes y balbucían torpemente acerca de la 'naturalidad' del poder político ${ }^{3}$. Pero con independencia de este descono-

1 Véase Carpintero, Francisco, Deber y fuerza: la Modernidad y el tema del deber jurídico, en Obligatoriedad y derecho. XII Jornadas de Filosofía Juridica y Social (Oviedo, Universidad de Oviedo, 1991), pp. 151-182. Disponible en la web franciscocarpintero.com.

2 Elementa juris naturae et gentium. Commoda auditoribus methodo adornata. Cum notis sacerdotii Andreae Cantoris Amato (Neapoli, 1829 [1737]). L. 2, \$ 129.

3 Sobre estas dudas y teorías tan sólo a medias, véase CARPINTERo, Francisco, El desarrollo de la facultad individual en la Escolástica, en CARPINTERO, Francisco (ed.), El derecho subjetivo en su historia (Cádiz, Universidad de Cádiz, 2003), pp. 35-288. Disponible en la web 
cimiento, esta línea argumental que reconocemos con fuerza en el siglo XIV, se arrastró con fuerza similar hasta alcanzar a teóricos como Heineccius o Daries. Fue como un organismo vivo que contagió a las distintas generaciones de los teóricos de los fundamentos del derecho. El individuo aislado, el derecho como realidad individual, los pactos como único fundamento de la vida reglada por el derecho, las leyes c o n s t i t u t i v a s de la sociedad política y las discusiones sobre el derecho de resistencia, fueron pasos de un mismo camino que tardó tiempo en madurar. Aludamos a ellos en los autores que fueron traducidos a diversos idiomas y que permiten -al menos, hasta cierto punto- entender el paso desde el siglo XVIII al XIX.

De entre los juristas más conocidos de este siglo hemos de exceptuar, al tratar del derecho de resistencia, a Emerico de Vatel y a Jean-Jacques Burlamachi. Vatel se volcó con el tratamiento jurídico del derecho internacional, y Burlamachi, hombre siempre pacífico y delicado, más preocupado por superar sus depresiones que no usar tonos enérgicos, prefirió no tocar este tema.

\section{Gotfried ACHENWALl (1719-1772)}

Uno de los autores más conocidos de este momento fue Gotfried Achenwall (1719-1772), el primer teórico de la economía como ciencia que tuvo Alemania, y el jusnaturalista quizá más editado del siglo XVIII. Hay que advertir que Achenwall no era amante de la rotundidad, de modo que su discurso se mueve normalmente y amablemente entre varios planos posibles. Enlaza con la tradición ya secular indicando que el Jus naturale se ocupa de los derechos y obligaciones naturales que los hombres tienen fuera del estado social ${ }^{4}$. Sigue la vieja regla, que encontramos ya en el siglo XVI, que indica que el derecho natural se ocupa del hombre solitario, pues la consideración científica del hombre ha de partir desde el individuo aislado; era lo que muchos jusnaturalistas de los siglos XVII y XVIII había llamado jus naturale absolutum para diferenciarlo del Jus naturale hypoteticum que se ocupaba del hombre bajo las hipótesis de vivir socialmente, fuera en la familia fuera en la sociedad política. Esta segunda parte del derecho natural era llamada por nombres distintos, por ejemplo, Jus sociale naturale, aunque la denominación que se consolidó en mayor medida fue la de Jus naturale hypotheticum.

Pero los hombres no vivimos aislados, y sólo conocemos personas viviendo en sociedades. Achenwall, en lugar de recurrir al Jus naturale hypoteticum, habla del Derecho Natural Social (Jus Sociale Naturale) o del Derecho Natural de las Sociedades (Jus Naturale Societatum). Porque el derecho natural, aplicado a las sociedades, logra el Jus Naturale Socialis, que nos enseña los derechos y obligaciones de los hombres que viven en sociedades ${ }^{5}$. Este derecho compone el Jus Publicum

franciscocarpintero.com. También, del mismo autor, La ley natural. Historia de una realidad inacabada (México, UNAM, 2013).

4 "Consideravimus parte operis huius priori iura atque obligationes naturales, quae in status hominum singulorum extra sociali seu naturali obtinent". Iuris naturalis pars posterior complectens ius familiae, ius publicum et ius gentium in usumauditorium ( $8^{\mathrm{a}}$ ed., Göttingen, 1781), $\$ 1$.

5 "Scientia legum naturalium posito status social observandarum vocatur jus sociale naturale 
Universale -explica Achenwall-y en su estudio se han distinguido autores como Sydney, Locke, Roehmer, Fritsch, Wolff, Iohannson, Rousseau, Heineccius ${ }^{6}$.

Siguiendo igualmente la tradición, él observa ante todo (doctrinalmente) p e r s o n a s independientes que sólo usan en sus relaciones mutuas el derecho simplemente natural en lo que compete a su conservación y a sus acciones justas; porque todas las personas, si las consideramos en su estado originario, son libres e independientes entre sí ${ }^{7}$. Y una vez constituidas las sociedades, existen acciones que no son reguladas por el civile imperium-civiliter adiaphora- en las que sobrevive la libertad natural, y es una libertad a la que podemos llamar li b e r t a d c ivi $1^{8}$. Es una declaración algo extraña en la que se deja llevar por la facilidad argumentativa; pues debiera haber indicado, positivamente, que existe la libertad natural en la sociedad civil y, en lugar de este estilo para exponer el tema, prefiere aludir a las libertades que permanecen como residualmente.

La libertad no es un valor absoluto. Junto a los hombres libres existen los esclavos que, cuando son manumitidos, vuelven a recuperar la libertad natural ${ }^{9}$.

Lo que él llamó Derecho Social Universal se ocupa de las obligaciones naturales que competen a los socios entre sí, distinguiendo las que les competen como socios de las que les competen como hombres ${ }^{10}$. Habla ante todo de socios y no de homines o de cives porque la sociedad ha sido constituida por un pacto, es decir, por el consenso común que es llamado "Pacto de la Unión Civil"11, por el que crean la convención o coëtus. Otro pacto distinto es el contrato que crea naturalmente el poder civil, de modo que el Gobernante tiene el imperio y la majestad que ha adquirido mediante el pacto con el pueblo, por el cual éste le transmite a aquel [el imperium civile] y se le somete. Tal acuerdo es llamado pacto de sujeción civil ${ }^{12}$. Reproduce, aunque quizá él no fuera consciente de ello, la vieja

(Ius Sociale Naturale, Ius Naturale Societatum). Ergo Ius Socialis Naturalis est Ius Naturale ad societates applicatum, docetque iura atque obligationes naturales, quae posita demum societate quadam particulari concipi possunt". Iuris naturalis pars posterior, $\$ 4$.

6 ACHENWALl, Iuris naturalis pars posterior, $\$ 88$.

7 "Quoniam gentes utuntur erga se invicem Iure mere Naturali; cuilibet genti ius competit in sui quae personae conservationem et in actiones suasiustas. Quamobrem omnes gens, si per se se in statu originario spectantur, sunt liberae et a se invicem independentes". Iuris naturalis pars posterior, $\$ 214$.

8 "Ergo dantur actiones subditorum civilium, quae imperium civili non subsunt, Actiones civiliter indiferentes residuum (civiliter adiaphora) respectu quarum subditis civilibus superstat naturalis libertas. Residuum libertatis naturalis, quod subditus civilibus qua talibus competit, vocatur libertas civilis". Iuris naturalis pars posterior, $\$ 107$.

9 "Actus, quo dominus servum ex potestate dominica dimittit, est manumissio. Quum dominus manumissione potestati dominica renuntiet: servus, qui manumittitur, redit in statum naturalem, et sit liber. Servus manumissus libertus vocitatur". Iuris naturalis pars posterior, $\$ 71$.

10 "Ius ergo Sociale Universale Internum traditiura atque obligationes naturales, quae socius erga se invicem competunt, et potissimum eas, quae ipsiscompetunt que talibus, qua iura atque obligationes vocantur 'stricte et simpliciter' sociales, et diversae sunt ab iis, quae sociis erga se invicem competunt, licet tantum ut homines considerentur, quippe haec iura atque obligationes sunt simpliciter naturales". Iuris naturalis pars posterior, $\$ 5$.

11 "Civitas vi originis et naturaliter constituitur pacto ultraneo, ideoque communi consensu eorum, qui in civitatem consociatur, quod pactum vocatur pactum unionis civilis". Iuris naturalis pars posterior, $\$ 91$.

12 "Quum imperium civile naturaliter pacto adquiratur, imperans civilis imperium et 
distinción medieval entre pactum unionis y pactum subjectionis. Los pactos por los que la sociedad adquiere su forma específica se llaman pactos fundamentales o leges (civitatis) fundamentales; no puede existir ninguna ciudad sin estar ordenada por las leyes fundamentales ${ }^{13}$.

Los hombres que contratan dan origen a un cuerpo distinto del que pueden formar las simples voluntades. Crean el poder y crean al gobernante, pero no pueden disponer sobre el poder. Tanto Daries como Nettelbladt dejaron muy clara esta cualidad del summum imperium, que va más allá de lo que pueden formar las fuerzas de las voluntades. Dicho sea incidentalmente, Hobbes tropezó en este tema, ya que explicó que los hombres crean voluntariamente el poder político, y hubo de añadir que tal poder es cualitativamente distinto de las voluntades que le han dado origen ${ }^{14}$, lo que no tiene sentido en un empirista que no reconoce la existencia de cualidades. El imperio de la sociedad mayor -prosigue Achenwallque en cuanto a su ejercicio no depende de ningún hombre, se llama i m p e r i o s u m o o summa potestas, y el imperante al que corresponde este poder es llamado $\mathrm{s}$ u $\mathrm{m} \mathrm{o}^{15}$. El Gobernante llega a ser tal $\mathrm{n}$ a $\mathrm{t}$ u $\mathrm{r}$ a $\mathrm{l} \mathrm{m}$ e n t e por el consenso común de los ciudadanos, al que podemos llamar pactum ordinationis civilis ${ }^{16}$.

Achenwall innova algo sea en la formación de términos nuevos, sea en su transmisión. Hasta entonces, (y también entonces: basta leer a Daries o Nettelbladt) los juristas habían distinguido la persona como persona, siempre persona privada, y las conditiones personarum o personas jurídicas: estas últimas p e r s o $\mathrm{n}$ a s estaban compuestas por los haces de los derechos y deberes que se agrupan en torno a una persona física, y así hablaban, por ejemplo, de la condición de comerciante. La persona como persona era siempre un ser de naturaleza $\mathrm{p} r \mathrm{i}$ v a d a y la persona jurídica era esencialmente pública, es decir, jurídica. Pero Achenwall llama persona públic a también a los ciudadanos a los que incumbe la administración de los asuntos públicos, y se oponen en este punto a las personas privadas o no públicas ${ }^{17}$. Tiende a delimitar una nueva esfera, autónoma, de lo

maiestatem habet ex pacto cum populo, qui in ipsum transfert imperium, atque ideo se ipsisubiciit. Unde talis conventio per exc. Vocantur pactum subjectionis (civilis)". Iuris naturalis pars posterior, $\$ 98$. Se apoya en Thomasius, Masius, Leyser, Frank.

13 "Pacta, quibus Civitas eiusque forma specifica constituitur, dicuntur pacta fundamentalia (civitatis) [...] appellantur quoque leges (civitatis) fundamentales. Nulla ita que datur civitas ordinata sine legibus fundamentalibus". Iuris naturalis pars posterior, $\$ 109$.

14 Este inglés declara que el poder político es mayor que los derechos de los ciudadanos. Es omnipotente, y debe ser llamado a b s o $1 \mathrm{u} t \mathrm{o}$. Leviathan, or the matter, form and power of a Commonwealth ecclesiastical and civil (London, 1839), Chap. VI, p. 80.

15 "Imperium societatis maioris, quatenus exercitium a nullius hominis imperio dependet, imperium summum (summa potestas), et hincimperans, cui id competitur, summus appellatur". Iuris naturalis pars posterior, $\$ 95$.

16 "Ordinatio igitur civitatis 'naturaliter' communicivium consensu, hinc iterum pacto perficitur, quod dici potest pactum ordinationis”. Iuris naturalis pars posterior, $\$ 92$.

17 "Et quoniam civis, cui negotium publicum administrandum incumbit, qua talis, dicitur persona publica, quae opponitur personae privatae seu non publicae" Iuris naturalis pars posterior, $\$ 121$. 
que es público. Este nuevo cuerpo social creado contractualmente dicta lo que se llama jus majestaticum ${ }^{18}$.

Si el pueblo no enajena definitivamente el imperio público y lo retiene él para sí origina una democracia (respublica democratica, respublica popularis, status popularis). Comparte con la aristocracia el nombre de respublica ${ }^{19}$. Dice tener en su contra a Machiavelo, Scioppius, y entre los monarcómacos a George Buchanan, Spetephanus Junius Brutus, Juan Boucher, Guillermo Refinaldus (William Raynold), Juan de Mariana, Johan Milton ${ }^{20}$. Él es un autor de Derecho Público Universal que cita a Ulricus Huber, lo que muestra que es un hombre equilibrado en el que no hay que esperar condenas fulminantes, pues Huber fue el politólogo al que se remitieron de forma especialmente abundante los autores conservadores del siglo XVII, hombre dado a citar a los españoles. Pero Achenwall no se deja llevar por tesis rotundas y sus declaraciones sobre la democracia muestra una ambigüedad sobre cuyo alcance no es fácil juzgar.

Explica que en la democracia existe un c o l e g i o p o p u la r (parlamento o gobierno colegiado) al que el derecho le compete de modo sumo, pleno y absoluto; este colegio se llama supremo (summum) y a él le compete la majestas ${ }^{21}$. A este gobierno o colegio popular se le ha trasladado todo el derecho (Jus universorum), y bajo este imperio se encuentran todos los ciudadanos y también aquellos que forman parte del colegio supremo. Porque en la república popular nadie es libre ${ }^{22}$. Parece que apunta a una tesis similar a la roussoniana. En la monarquía hay dos partes distintas que ocasionalmente pueden estar enfrentadas y se puede hablar de libertad ante el monarca. Pero en la democracia no existe esa o t $r$ a parte: el poder civil lo tienen todos por igual, y las obligaciones jurídicas afectan a todos igualmente.

El fin del poder civil es hacer posible la felicidad pública, es decir, la salud, la seguridad, el régimen y la administración de la república ${ }^{23}$. Desde esta obligación civil de los gobernantes fluye el derecho de los súbditos para que él cuide de la salvación pública (¿cómo traducir salus publica?), no la descuide ni mucho menos

18 Iuris naturalis pars posterior, $\$ 99$.

19 "Si populus retinet imperium publicum, oritur democratia (respublica democratica, respublica popularis, status popularis [...] Aristocracia et democratia communi nomine respublica 'stricte' vocantur". Iuris naturalis pars posterior, $\$ 110$.

20 Iuris naturalis pars posterior, $\$ 206$.

21 "Quam obrem in democratia collegio populari imperium publico (si nempe simpliciter translatum) competit tanquam summum, plenum atque absolutum, immo cum iure exercendi imperium solet ipsi simul competere ius omne universorum [...] Hinc collegium populare vocatur supremum (summum), eique competit maiestas". Iuris naturalis pars posterior, $₫ 174$.

22 "Quoniam itaque in collegium populare translatum ius universorum; eius imperio sub sunt singuli cives quicumque, seu omnes cives singulatim spectati, ideoque etiam singuli quique, qui sunt membra collegi supremi. Quare in republica popular inemo singulus est liber". Iuris naturalis pars posterior, $\$ 175$.

23 "Eodem que significatu et publica salus, securitas, prosperitas, régimen, administratio reipublicae”. Iuris naturalis pars posterior, $\$ 102$. 
la destruya ${ }^{24}$. El poder civil se extiende hasta lo que exige la foelicitas pública ${ }^{25}$. El pueblo puede resistir al tirano y obligarle a actuar para que se abstenga de los comportamientos tiránicos y para que contenga su actuación dentro de los límites de la salus publica ${ }^{26}$. No parece que Achenwall sea el innovador que introdujo a la publica foelicitas como meta del poder: pero sí hay que destacar que esta tesis es especialmente propia de este siglo, que es el propio del Despotismo Ilustrado, que trataba de hacer felices a los ciudadanos. Apenas aparece en los autores de los siglos anteriores.

$$
\text { JoAquín Jorge Daries (1714-1791) }
$$

Cita a buena parte de las autoridades de los siglos XVII y XVIII, incluso a esos autores del siglo XVII que parecen no ser conocidos por nadie fuera de los historiadores alemanes. Como jurista práctico aunque con fuertes ambiciones teóricas, también se apoya en el derecho romano ${ }^{27}$. Siguiendo el estilo moderno concibe al jus como una facultad, y en el afán que sitúa en el resistere o persequi, parece un nominal de siglos atrás o uno de los últimos escolásticos españoles, como Gabriel Vázquez de Belmonte o Luis de Molina ${ }^{28}$, quienes entendían que la proprietas constituía la vertiente procesal del dominium, es decir, la facultad para retener y para perseguir.

Pronto se aprecia su estilo entre jusnaturalista y moderno cuando indica que "Existen en nosotros impulsos esenciales que tienden a hacer lo que es recto, y a estos estímulos se les puede llamar con toda propiedad Jus naturae. Pues la voz derecho indica lo mismo que facultad o impulso para hacer, y por este motivo podemos decir que el Jus naturale es lo que la naturaleza enseñó a todos los animales" 29 . Esta vuelta directa al derecho romano, cuando Ulpiano declara que "Jus naturale est quod natura omnia animalia docuit", anima al que posee espíritu jurisprudencial.

Este derecho natural puede ser entendido en sentido subjetivo (subjetive sumptum), y designa a los estímulos naturales para hacer las cosas que son rectas ${ }^{30}$. Y

\footnotetext{
24 "Ex hac imperantis civilis obligationis effluit ius subditorum civilium, ut salutem publicam actus curet, non negligat, multo minus evertat". Iuris naturalis pars posterior, $\$ 103$.

25 "Imperium civile extenditur, quousque patet felicitas publica". Iuris naturalis pars posterior, $\$ 106$.

26 "Populus igitur tyranno resistere eumque coercere potest, ut se abstineat a tyrannide, atque intra salutis publicae limites reducat régimen". Iuris naturalis pars posterior, $\$ 204$.

27 DARIES, Joachim Georgii Institutiones jurisprudentiae universalis in quibus omnia juris naturae, socialis et gentium explanantur (6a ed., Jenae, 1764).

28 "Hanc in cogitatione serie ius idem significare, quod facultas agendi, habendi, utendi, fruendi aliqua res. Quam ad significationem spectant formulae, jus suum tueri, retinere, recuperare, persequi, de suo jure concedere, decedere, remittere, uti suo jure, esse sui iuris, et quae reliquae". Institutiones jurisprudentiae, Praefatio, $\$ 4$.

29 "Sunt itaque in nobis stimuli naturales seu conatus essentiales, ad id agendum, quod rectum est, stimuli illietian non improprie sed proprie jus naturae, si nimirum ius idem significet, quod facultas seu conatus agendi, vocantur, ideoque hacratione defendere possumus, ius naturale esse, quod natura omnia docet animalia". Institutiones jurisprudentiae, Praefatio, $\$ 5$.

30 "Ius naturae, quod natura omnia docet animalia, est quid jus naturae subjective sumptu
} 
así surgen esas acciones a las que nosotros mismos nos determinamos o a las que nos lleva nuestra constitución humana. Si hacemos lo que tenemos en nuestra potestad, obramos sponte, libremente ${ }^{31}$. Utilizando terminología escolástica, explica que la libertad es el principio eficiente intrínseco que determina las acciones sin necesidad de recurrir a otros principios. A esto lo llamamos 'espontaneidad', Wi$l l k \ddot{u} h r^{32}$. Así, la facultad, en cuanto determinada a una acción, es llamada jus (Recht, Befugniss), de modo que el estado moral se puede definir como el conjunto de los derechos de un sujeto, que se le añaden a su existencia ${ }^{33}$, y la libertad es la fuente de la moralidad ${ }^{34}$. Es obvio que, como nadie posee un privilegio para normar la conducta de otro (una frase muy de Gundling que explicaba que "Voluntas tertii ist nicht voluntas nostra" ${ }^{35}$ ), todo derecho que una persona posea sobre otra ha de ser un derecho adquirido, porque el estado de naturaleza es un estado de igualdad ${ }^{36}$.

$\mathrm{Su}$ formación jurídica se hace notar de una forma desconocida en los otros jusnaturalistas, porque no confía la definición o descripción del jus únicamente a las facultates, dominia, o libertates a las que lo dejaron reducidos otros tratadistas del derecho. Este hecho requiere una explicación singular porque él mismo ha tenido una historia muy singular. Los primeros grandes teóricos del nuevo Jus naturale -hay que reparar en Fernando Vázquez de Menchaca, Luis de Molina y Francisco Suárez- hablaron de una ley natural rígida y eterna que concedía derechos de libertad, de forma que cada cual tiene derecho a beber su bebida -sigo literalmente los ejemplos de Molina-, a comer su comida o a vestir su vestido. La ley natural solo otorga libertades según lo expresamente alegado por estos grandes apologetas de la libertad individual. Pero habría que haberles objetado que los derechos de propiedad individuales tanto establecen mi derecho a comer mi comida como excluyen a los otros de lo que es mío, de modo que si puedo

vocari potest, nil aliud esse quam stimulus naturales ad ea agenda, quae recta sunt". Institutiones jurisprudentiae, Praefatio, $\$ 5$.

31 "Eiusmodi ad actiones aut nos ipsos determinamus, aut a constitutione nostra determinamus. Alia itaque sunt actiones, quas in postestate nostra habemus, aliae, que in eadem minimesitae sunt. Si agimus, quod in potestate nostra habemus, sponte agimus". Institutiones jurisprudentiae, $\$ 7$.

32 "Principium efficiens intrinsecum, quo sine aliorum principiorum efficentium extrinsecorum concursu ad diversa se determinare potets actiones, 'Spontaneitas' (der Willhühr) vocatur". Institutiones jurisprudentiae, $\$ 44$.

33 "Eiusmodi facultas, quatenus determinatam quandam actionem spectat, vocantur ius (das Recht, die Befugniss), statum ergo moralem definire possumus, collectionem jurium, quae in subjecto quodam, ut existentia summuntur". DARIEs, Institutiones jurisprudentiae, $\$ 9$. En el $\$ 52$ de esta misma obra añade que "Facultas sese praevia consultatione ad aliquid sponte determinandi vocatur 'libertas".

34 "Moralium actionum fons est libertas, qua agere non possumus, nisi volendo atque nolendo". DARIES, Institutiones jurisprudentiae, $\$ 74$.

35 "[...] denn voluntas tertii ist nicht voluntas nostra [...] Factum tertii nobis non imputatur, quia non sumus auctores actionis nec physici, nec morales". Erläuterung über Samuelis Pufendorfizwey Bücher De Officio hominis etcivis (Hamburg, 1744), L. I, cap. 1, \$\$ 26-27.

36 "Nemini eiusmodi in alterum competere potest esse jus, nisi adquisitum. Quicquid enim nobis competit, sed non per naturam, id inter acquisita referri debet. Iura vero perfecta atque affirmativa in alterum nos non posse habere naturam, inde manifestum est, quoniam status naturalis est status aequalitatis, ideoque omnes omnino homines naturaliter spectari eadem habent jura”. Institutiones jurisprudentiae, $\$ 518$. 
disfrutar de mis derechos es porque excluye a todos los otros de lo que es mío. Daries establece que todo derecho nace desde una obligación: "Omne jus oritur ex obligatione". Pues el derecho es una facultad moral de hacer que resulta desde una posibilidad moral y hay que suponer que nace desde una ley. Tengamos en cuenta que, desde Hobbes, se había impuesto en un fuerte sector del derecho natural la tesis de "Jus seu libertas, lex quae constringit". "Por lo que -continua Daries-como el fundamento de las leyes es la obligación, es manifiesto que ningún derecho puede existir sin obligación. Por esto, los doctores del derecho natural suelen decir que el jus es un correlato de la obligatio, por lo que donde no hay derecho no hay obligación" ${ }^{37}$.

$\mathrm{Su}$ actitud ante el fundamento deóntico de las facultades en que consiste la libertad es algo confuso. Él depende mucho de Thomasius y Christian Thomasius no estuvo muy preocupado por la teología, sino por el bene vivere eudemonista propio del siglo XVIII. Daries parece querer guardar las formas e indica que "Obligatio naturalis est etiam obligatio divina" 38 . Su pensamiento es confuso: afirma la moralidad intrínseca de las acciones ${ }^{39}$, pero en toda esta zona de sus "Institutiones" se remite a Thomasius.

Hace suya la doctrina del principium unicum y entiende que todos los razonamientos pueden ser reducidos a una figura primera de los silogismos que es la 'propositio principalis' o la 'mayor universal'40. El primer principio del derecho natural es buscar la perfección del hombre, y éste es el fundamento universal, doméstico, primero y adecuado de las leyes naturales ${ }^{41}$. Es un correlato de su tesis más amplia: la finalidad del hombre es su perfección ${ }^{42}$. No le plantea problemas descender desde esta tesis primera a las verdades más concretas, ya que él entiende que tanto el mundo como el hombre forman un sistema, el 'systema entium', que se constituye porque las operaciones de uno vienen determinadas por las actuaciones de otros ${ }^{43}$. Y la ciencia del derecho es la búsqueda de los fundamentos que permiten demostrar y aplicar las leyes civiles adecuadamente; si no es así, se convierte en un arte de le g u l e y o s: leiuleiorum dicam ${ }^{44}$.

37 "Et enim jus est facultas agendi moralis, per consequens ex possibilitate morali et han cobcausam ex lege concipitur. Quare, cum legis fundamentum sit obligatio, nullum jus sine obligatione locum habere, manifestum est. Summa ergo cum ratione I. N. et $G$. D octores ius obligationis correlatum vocare solent. Ubi igitur nulla obligatio, ibi nullum jus, et ubi nullum jus, ibi nulla obligatio". Institutiones jurisprudentiae, $\$ 152$.

38 Ibíd., $\$ 77$.

39 Ibíd., $\$ 66$.

40 "Omnia ratiocinia ad primam syllogismorum figura reducci possunt, qua in figura propositio principalis seu maior universalis esse debet”. Institutiones jurisprudentiae, $\$ 140$.

41 "Propositio: Fac ea, quae te perfectiorem efficiunt; et omitte ea, quae te imperfectiorem reddunt, est vera lex naturalis". DARIES, Institutiones jurisprudentiae, \$143. "Propositio 143 demonstrata est legum naturalium fundamentum universale, domesticum, primum atque adaequatum”. Institutiones jurisprudentiae, $\$ 144$.

42 Institutiones jurisprudentiae, $\$ 14$.

43 "Mundum ut et hominem esse systema, variis argumentis in Metaphysica corroboratur, est vero 'systema entium' unum, quod entibus ita connexis, ut eorum unum operationes alterius determinare possit, constituitur”. Vid. Mechanologiam, $\$ 1$ seqq. Institutiones jurisprudentiae, $\$ 57$.

44 Institutiones jurisprudentiae, $\$ 49$. 
Por lo demás sigue los carriles corrientes en esta época. Los hombres son iguales en el derecho ${ }^{45}$. Pero no se puede tomar esta tesis al pie de la letra porque él es monárquico y se deja guiar por los usos comunes de la monarquía moderna. Así, escribe que, como el imperio es mayestático, el monarca puede conceder privilegios $^{46}$ : una tesis que no hubiera gustado a Francisco de Vitoria ni, mucho menos, a Fernando Vázquez de Menchaca. Su sentido patrimonial del poder es fuerte, y esto le lleva a opinar que las obligaciones políticas de los ciudadanos han de ser deducidas desde el imperio del gobernante ${ }^{47}$. En línea similar añade que el ciudadano no es libre para abandonar su país sin el consentimiento de su Príncipe ${ }^{48}$

Existen dos estados, uno de soledad y otro social ${ }^{49}$. La injusticia consiste en impedir que otro pueda ejercer plenamente su derecho ${ }^{50}$. El fin de la ciudad es hacer posible la seguridad ${ }^{51}$, por lo que las acciones no-civiles han de ser negativas y tienen que consistir en omisiones ${ }^{52}$. Admite la licitud de la esclavitud en la sociedad heril ${ }^{53}$.

Aproximándonos a lo que más interesa, mantiene que, en lo que hace a la democracia, la majestas está en todo el pueblo, y los ciudadanos, considerados individualmente, no gozan de majestad ${ }^{54}$. En este tipo de régimen político es necesario que haya comicios porque la forma mayestática no puede ser ejercida sino por la reunión del pueblo ${ }^{55}$, de modo que los ciudadanos quedan perfectamente obligados "con obligación p e r fe ct a, esto es, coactiva" por lo que decida la

45 "Posita eadem ratione suficiente idem etiam inde sequitur". Institutiones jurisprudentiae, $\$ 13$.

46 "Adamus quadam de privilegiis. Ex iis, quae de civitate hac tenus explicavimus, cives subditos, qua tales, esse in statu aequalitatis". DARIES, Institutiones jurisprudentiae, \$709a. "Sequitur inde, ut privilegia dare nequeat, nisi qui habet ius in cives, qua tales; quam obrem, cum huiusmodi ius sit majestaticum, soli etiam civitati imperanti competit ius dandi privilegia. Quod etiam ex potestate legislatoria sequitur”. Institutiones jurisprudentiae, $\$ 709 \mathrm{~b}$.

47 "Obligatio imperio civitatis subiectorum, qua talium, ex iure imperantis debet deduci". Institutiones jurisprudentiae, $\$ 714$.

48 "Fieri non potest, ut cives subiectus sine consensu imperantis iuste emigret [...] non potest liberari sine consensu ejus, cui obligatus est”. Institutiones jurisprudentiae, $\$ 740$.

49 "Priore respectu status ille naturalis status solitudinis, posteriori vero status socialis absolutus a Doctoribus I. N. et G. vocatur". Todo lo que explicará se referirá a este estado absoluto. Institutiones jurisprudentiae, $\$ 15$. "Naturalis jurisprudentia, quae statui social absoluto officia praescribit, 'simpliciter jurisprudentia' vocatur. Quatenus vero statum sociale hypotheticum describit, est “jurisprudentia socialis”. Institutiones jurisprudentiae, $\$ 35$.

50 "Qui impedit, quo minus ius suum possit exercere, alterum laedit". Institutiones jurisprudentiae, $\$ 329$.

51 Ibíd., $\$ 656$.

52 "Obligatio publica non-civilis tantummodo est negativa, civilis vero posse esse positiva [...] Eiusmodi itaque obligationes publicae objectum non sunt nisi actiones omissivae". Institutiones jurisprudentiae, $\$ 713$.

53 Ibíd., $\$ 830$.

54 "Quod democratia mattinet, maiestasest in totopopulo, cives igitur sigillatim considerari majestate non gaudent". Institutiones jurisprudentiae, $\$ 749$.

55 "Necesse est, ut in democratia comitia habeantur [...] Hac itaque in civitatis forma jura majestatica non possunt exerceri, nisi in conventu populi". Institutiones jurisprudentiae, $\$ 751$. 
mayor parte ${ }^{56}$, y todos los votos tienen el mismo valor ${ }^{57}$. Se vuelve algo confuso cuando trata de los límites del poder; el poder mayestático depende de la esencia de la majestad o desde el consenso de los ciudadanos; en el primer caso los límites son naturales, y en el segundo supuesto provienen de un pacto ${ }^{58}$. Los límites han de existir porque "En la sociedad necesaria la majestas está naturalmente limitada, y no podemos buscar otra razón para estos límites" 59 .

Como jurista que es, entiende sin problemas que lo que hay que medir es tanto lo medido como la regla de mensura ${ }^{60}$; responde al viejo dicho escolástico que establecía que "Mensura non videtur esse nisi mensuratum". El Gobernante es una persona que tiene un of i c i o (officium) o munus: "Todos aquellos estados o situaciones en las que hay que resolver ciertos problemas y se está obligado a ello con obligación perfecta, se dice 'munus'. Si partimos desde la obligación llegamos al officium y por esto este estado recibe también el nombre de o f i c i o. Y quien está obligado por este motivo es llamado oficial" 61 . Ésta no es una noción que se limite al derecho privado o con la que se designe únicamente a quien actúa en nombre de la majestas: en la ciudad, los oficios son de dos tipos, privados y públicos $^{62}$, con lo que deja claro el carácter ambivalente de los cargos públicos, en los que siempre el deber antecede al derecho.

De acuerdo con esta visión de la obligación jurídica (o del derecho, que en este punto tanto da hablar de jus como de obligatio), los límites de la majestad (no alude al derecho de majestad) bien dependen de la esencia de la majestad bien del consenso de los ciudadanos; en el primer caso hablamos de límites naturales, y en el segundo de límites pactados ${ }^{63}$. Quienes eligen a los Gobernantes pueden proponer reglas a las que el gobierno ha de atemperar el modo de ejercer los jura majestatica, y estas reglas se llaman leges fundamentales o capitulaciones según la forma política de cada ciudad ${ }^{64}$.

Sus declaraciones sobre la tiranía tenían que ser muy ligeras en aquel pequeño

56 "Cives in democratia perfecte obligati sunt, ut in comitiis ad maioris partis sententia maccedant”. Institutiones jurisprudentiae, $\$ 757$.

57 "In democratia vota civium non aestimari sed numerari debent". Institutiones jurisprudentiae, $\$ 759$.

58 "Limes ille majestatis vel dependet ab essentia majestatis, vel a civium consensu, priori ratione ejusmodi limes dicitur naturalis, posteriori modo vero pactitius". Institutiones jurisprudentiae, $\$ 768$.

59 "In civitate necessaria majestas naturaliter limitata est, et alia quadam ratione limites maiestatis in eadem cogitar inequeunt”. Institutiones jurisprudentiae, $\$ 788$.

60 "Quicquid rei certam dat mensuram, id eandem limitat". Institutiones jurisprudentiae, $\$ 785$.

61 "Status, in quo quiscerta quaedam negotia expedienda atque conficienda perfecte obligatus est, dicitur munus. Quoniam ab obligatione ad officium valet consequentiam, eiusmodi etiam status 'offici' nomen accepit. Et qui hac ratione obligatus est, 'officialis' vocatur'. Institutiones jurisprudentiae, $\$ 704$.

62 "In civitate munera duplici sunt generis, privata scilicet et publica". Institutiones jurisprudentiae, $\$ 705$.

63 "Limes ille majestatis vel dependet ab essentia majestatis, vel a civium consensu, priori ratione ejusmodi limes dicitur naturalis, posteriori modo vero pactitius”. Institutiones jurisprudentiae, $\$ 768$.

64 "Si, quiim perantem eligunt, propositiones quasdam constituunt, quibus imperans modum excercendi iura maiestatica attemperare debet, propositiones illae in civitate successiva leges fundamentales et in civitate elictiva capitulationes vocantur". Institutiones jurisprudentiae, $\$ 791$. 
mundo monárquico y versallesco, y más en su caso, que era consiliario aúlico de cámara de Prusia. Se limita a indicar que si el Gobernante abusa del derecho de majestad y trata de oprimir a toda la ciudad, ése tal es llamado tirano ${ }^{65}$. Para denunciar opiniones equivocadas se remite a la enumeración que hizo Michael Gribner unos años antes, a saber: a) el sumo imperio siempre es del pueblo; b) el príncipe que gobierna mal puede ser forzado por el pueblo; c) la totalidad del pueblo es superior al príncipe; d) cualquiera puede resistir al Príncipe si pide cosas injustas; e) los magistrados inferiores se pueden oponer al Rey; f) el monarca absoluto es un tirano ${ }^{66}$.

\section{Daniel NetTelbladt (1719-1791)}

Es otro de los grandes juristas de este momento en cuyas páginas el jurista de hoy nada a gusto, porqueno es un filósofo como Wolff, ni un diplomático como Vattel, ni un personaje con especial relevancia política, sino un profesor en una Facultad de Derecho. Del mismo modo que Daries, como jurista aficionado a indagar en las cuestiones teóricas, conoce bien a los que trataron el derecho natural en el siglo anterior. Incluso propone una breve historia de la disciplina del derecho natural.

Según él, el iniciador de la Juris naturalis diciplina fue Hugo Grocio, que tuvo unos antecedentes pocos precisos en los tiempos anteriores. Cita, como predecesores, a Hemming, Gentili o Winckler ${ }^{67}$. Como era usual entre los protestantes ilustrados, no hace ninguna referencia ni a los escolásticos, ni a los juristas del Jus Commune, ni a los teóricos del siglo XVI tales como Hopper, los Bolognettus, Conan o Tholosanus ${ }^{68}$. Les siguen los autores del siglo XVII que o bien hablaron del derecho natural o bien hicieron teorías sobre la mejor convivencia posible; cita entonces a Selden, Hobbes, Ziegler, Pufendorf, Cocceius, Thomasius, Koehler, Glafey o Wolff ${ }^{69}$. El gran hombre había sido Samuel Pufendorf, que acabó la obra que había comenzado Grocio, que acabó con la barbarie de los tiempos escolásticos y dio al derecho forma sistemática ${ }^{70}$. Tiene muy buena impresión de Thomasius y presenta como "Immortale orbis litterari decus", a Christian Wolff. El primero que siguió los principios de Wolff fue, según él, Henricus Koehler; continúa mencionando a otros autores alemanes ${ }^{71}$. Hizo una amalgama extraña de autores, porque no parece lícito yuxtaponer a personas como a Cocceius y Thomasius, o a Wolff y Koehler. Lo que sí queda patente en esta enumeración de fuentes es que él circunscribe sus explicaciones primero a los protestantes, y después a

65 "Si civitati Imperans abusu jurium majestatico rumuni versam civitatem opprimere conatur, hocce ex conatu nominatur Tyrannus”. Institutiones jurisprudentiae, $\$ 703$.

66 Ibíd., $\$ 766$.

67 Systema elementare universae jurisprudentiae naturalis in usum praelectionum academicarum adornatum, (3 a ed., Halae Magdeburgicae, 1767), $\$ \$ 22$ y 23.

68 Sobre este problema, vid. mi estudio La Modernidad jurídica y los católicos, en Anuario de Filosofía del Derecho, 5 (1988) pp. 383-412. Disponible en la web franciscocarpintero.com.

69 Systema elementare, $\$ 26$.

70 Ibíd., $\$ 31$.

71 Ibíd., \$\$ 32 y 36. 
los protestantes alemanes: un ámbito literario pequeño que, una vez conocido, le permite moverse con bastante soltura al tener claros sus puntos de referencia.

Hace varias divisiones de juristas: empíricos y racionales; teóricos y prácticos; de escuela o eclécticos; pragmáticos y no pragmáticos; de primer orden y segundo orden. En los que son peritos en derecho natural no se dan estas divisiones ${ }^{72}$. Una vez guardadas las espaldas porque él es experto en derecho natural -en jurisprudentia naturalis, para ser más preciso- puede proceder con más desenvoltura.

Comienza tratando la noción de persona. Este término, en sentido general, significa lo mismo que hombre, pero en el modo de trabajar el derecho designa al hombre considerado bajo cierto estado. Inmediatamente añade el tratamiento de los estamentos, que son cualidades por las que hombres diversos gozan de diversos derechos y obligaciones ${ }^{73}$. La 'naturalis jurisprudentia' no presupone a los hombres viviendo en la república o en un cierto estado, sino que se ocupa de los hombres en cualquiera de sus condiciones ${ }^{74}$. Más adelante en esta obra distingue, como 'estados naturalmente puestos', el estado de embrión, de sexo, de edad, de demencia y de discapacidades ${ }^{75}$, lo que supone una notable concesión al espíritu jurisprudencial.

Con su doctrina sobre la persona ha puesto el fundamento primero para comenzar el tratamiento propiamente jusnaturalista. Desde luego, no es un fundamento muy claro, porque él mismo reconoce que hay que distinguir entre jóvenes y ancianos, o entre sanos y discapacitados, reconoce también derechos que son irreductibles a tipos más amplios, como es el caso de la patria potestad, que debe ser distinguida de las otras sociedades, cosa que no hace el vulgo ${ }^{76}$. Ese v u 1 g o que él menciona ¿está compuesto por los compañeros de claustro?; porque la gente normal está ocupada con su trabajo y con el cuidado de su familia y no se cuida de distinguir teóricamente los distintos tipos de sociedades. A diferencia de los jusnaturalistas especialmente del siglo XVII, no sitúa ante su vista una p e r s o n a abstracta a la que, sin más, pueda atribuir una voluntad libre y explicar la formación del orden jurídico mediante una cascada de contratos, como hizo Henricus Koehler en la mayor medida, que redujo todo el orden jurídico (también la patria potestad) a pactos. Teniendo ya la primera base para el tratamiento de la jurisprudencia natural, procede a explicar en qué consiste esta jurisprudencia.

Procede con rigor entre geométrico y militar y explica que las notas de este modo de conocer el derecho son: 1) todas las verdades que ella considera son naturales; 2) la fuente para su conocimiento es la naturaleza y esencia de las co-

72 "Generales eruditorum divisiones in empiricos et rationales; in theoreticos et practicos; in sectatores et eclecticos; in pragmaticos et non pragmaticos; in primi et secundi ordinis; quoad juris naturalis peritos locum habent, nec dantur praetereas speciales divisiones". Systema elementare, Praecognita, $\$ 8$.

73 "Persona in sensu generaliidem est ac homo. In sensu speciali vero sunt persona nomine venit, homo consideratus sub certo statu. Status autem hoc loco est qualitas, secundum quam homines diversis juribus et oblitationes utuntur". Systema elementare, $\$ 43$.

74 "Jurisprudentia naturalis non praesupponit homines in reipublicae seu in statu civili viventes [...] in quacumque conditione vivat homo”. Systema elementare. Pars I, Praecognita, $\$ 7$.

75 Systema elementare, $\$ \$ 777-783$.

76 Ibíd., $\$ 795$. 
sas; 3) el único medio para conocerlas es el uso de la razón sana; todas las reglas son necesarias ${ }^{77}$. El criterio supremo bajo el que todas estas verdades han de ser inordinadas es un principium unicum algo singular: hay que hacer las cosas que "ex rerum natura et essentia demonstrari potest", y hay que omitir las contrarias ${ }^{78}$. $\mathrm{O}$, por decirlo de una forma más completa, hay que partir desde la esencia y las naturalezas de las cosas existentes de modo que su principium cognoscendi sea la sana razón ${ }^{79}$. Ya que alude a la esencia de los entes, explica que la sustancia de una cosa es aquello que puede ser concebido como lo perdurable en esa $\operatorname{cosa}^{80}$.

Daries, desde su aprecio a Pufendorf, Thomasius o Koehler, parece inclinarse hacia un lado muy concreto del Jus naturale, el individualista, que es nominalista y contractualista. Pero como jurista no deja de sorprendernos, como cuando distinguió a las personas según su edad, su salud, etc. Vuelve a llamar la atención cuando trata expresamente el concepto del deber, y esto requiere una breve explicación. Buena parte de los jusnaturalitas del siglo XVII habían negado la existencia del deber, que lo dejaron reducido al miedo ante la sanción prevista en la ley o al hecho objetivo de la ley va acompañada de una sanción para el caso de su incumplimiento $^{81}$. Thomasius hizo desaparecer la noción del deber tras su concepto de imputatio. Una creación suya en la teoría del derecho), ya que la imputación de la ley a la acción o desde ésta a aquella, volvía superflua cualquier otra categoría o noción que explicara el porqué se aplicaba una ley a un hombre ${ }^{82}$. Pero Daries recupera esta noción polémica desde hacía un siglo y explica que el deber es la necesidad de hacer, esto es, la imposibilidad de actuar de un modo distinto al que lo hacemos, y se llama moral si proviene desde una ley; la necesidad de actuar moralmente es llamada obligación si es pasiva, a la que se opone la activa, que es la conexión del motivo con las acciones ${ }^{83}$. La suya fue una actitud -al menos en este punto- provocadora. Por lo demás, vuelve a los carriles normales entonces y explica que el deber fundamental es el de hacer todo aquello que nos hace más perfectos y evitar las conductas que vuelven el suum externum más imperfecto ${ }^{84}$.

77 Explica "1) omnes veritates, quae jurisprudentia naturalis ambitu suo, esse naturalis; 2) fonte mearum unicum esse rerum naturam et essentiam; 3) medium eas cognoscendi unicum esse sanae rationis usum; 4) omnes earum rationes esse necessarias". Systema elementare. Pars. I, Praecognita, $\$ 6$.

78 Systema elementare, $\$ 19$.

79 "Principium fiendi legem naturalium esse rerum naturam et essentiam existentem, principium cognoscendi earum vero esse sanae rationis usum”. Systema elementare, $\$ 137$.

80 "Rei substantia dicitur, quod tanquam perdurabile in re concipi potest". Systema elementare, $\$ 124$

${ }^{81}$ Vid. mi estudio Deber y fuerza: la Modernidad y el tema del deber jurídico, en Obligatoriedad $y$ derecho. XII Jornadas de Filosofía Jurídica y Social (Oviedo, Universidad de Oviedo, 1991), pp. 151-18

82 Vid. mi estudio Imputatio, en Rivista Internazionale di Filosofia del Diritto, 81 (2004) pp. $25-78$.

83 "Necessitas agendi, id est impossibilitas aliter agendi quam agimus, dicitur tum moralis, si venit ex lege. Necessitas vero agendi moralis vero dicitur obligatio, nimirum passiva, cui opponitur activa, quae est connexio motivi cum actione”. Systema elementare, $\$ 136$.

84 "Praecipua est originaria hominis obligatio naturalis connata est, quod, quatenus in sua potestate est, facere debeat quae se statum que suam externum reddunt perfectiorem, omittere vero quae se statumque suum externum reddunt imperfectiorem”. Systema elementare, $₫ 186$. 
También, en una línea más jurisprudencial, entiende que la facultad de hacer, esto es, la posibilidad de actuar, se llama moral si viene desde una ley. Una facultad de obrar moral se llama jus en sentido subjetivo, al que se le opone el jus en sentido objetivo. Yo hablo ahora del derecho subjetivo, que es el derecho considerado simpliciter" $"$.

Los elementos para el juicio se van completando: la persona, el deber, la perfección personal. Pero la época demandaba más para las personas, concretamente quería el reconocimiento expreso de su libertad. "La libertad natural es un derecho común para determinar nuestras acciones según nuestro arbitrio" ${ }^{86}$. A esta libertad le añade polémicamente lo que los medievales llamaron la Communis omnium possessio, e indica que la libertad natural y aquella comunión primera son derechos 'connatos, es decir, dados al hombre naturalmente ${ }^{87}$. Resulta de este modo que los 'derechos generalísimos' consisten en la libertad natural, la ausencia propiedades o communi primaeva, el dominio, el derecho a la seguridad, etc. ${ }^{88}$.

Entre estos derechos hay que incluir a la libertad de conciencia. Escribe, algo inseguro del terreno que pisa, que a la libertad de conciencia le repugna la coacción del que quiere imponer el asentimiento a dogmas religiosos; pero no va contra esta libertad obligar a enseñar públicamente alguno de estos dogmas ${ }^{89}$. Sucede que las cosas de la religión, sacras, no pueden estar sometidas al gobierno civil; hay que distinguir entre las cosas sacras internas y externas y las que constituyen objetos de las conciencias y las que no. Por lo que se refiere a las 'sacras internas' y que pertenecen a las conciencias, no recae sobre ellas ni coacción ni imperio ni pactos ${ }^{90}$. Esta declaración fue bastante audaz en aquel momento y, quizá para compensar, incluye -en la más pura tendencia galicana- un breve y minucioso tratado de derecho canónico.

Este reconocimiento de la libertad no quiere decir que Nettelbladt se salga de su época. Cargó las tintas en la defensa de las libertades pero siguió admitien-

85 "Facultas agendi, id est, posibilitas agendi, dicitur moralis si venit ex lege. Facultas agendi moralis vero dicitur ius, quando subjective sumitur, cui opponitur ius objetive sumtum. Hic loquor de iure subjective sumto, quod et simpliciter ius dicitur". Systema elementare, \$229. Daries usa con facilidad el término $\mathrm{s}$ u b j e t i v o, aunque la creación y divulgación de la expresión d e r e c ho s u b j e t i vo es más tardía. Vid. el estudio del Prof. A. Guzmán Brito, Historia de la denominación del derecho-facultad como 'subjetivo', en Revista de Estudios Histórico Jurídicos, 25 (2003) pp. 407-443.

86 "Libertas naturalis est ius commune actiones nostras determinandi pro nostro arbitrio". Systema elementare, $\$ 255$.

87 “Libertas naturalis et communio primaeva sunt iura connata". Systema elementare, $\$ 259$.

${ }_{88}$ "Ad iure generalisssima referri possunt libertas naturalis eum communione primaeva, dominium, ius securitatis, indemnitatis et necessitatis, unde nunc de his iuribus sigillatim agendum". Systema elementare, $\$ 254$.

89 "Libertas conscientia eitaque repugnat coactio ut quis dogmatibus religionis assensum praebeat [...] Ast conscientiae libertati non repugnat, si quis obligatur ad hoc vel illud dogma religionis publice docendum". Systema elementare, $\$ 1057$.

90 "Religionem seu sacra, coactionis, pactorum et imperii obiectum esse non posse, in genere dici nequit: sed potius hic distinguendum est inter sacra interna ex externa, et ea quae res conscientiae sunt, vel non. Quoad sacra interna enim, et ea quae res conscientiae sunt, nec pacta nec coactio, nec imperium locum habet". Systema elementare, $\$ 1058$. 
do -como era usual entonces- la licitud de la esclavitud en la sociedad heril y la existencia de los estamentos. La esclavitud no es natural (non esse a natura) sino que es creación artificial humana ${ }^{91}$. En la 'existimación civil' influyen las clases de los ciudadanos o Stände, que son prerrogativas que se transmiten por nacimiento y que conllevan distintas dignidades civiles ${ }^{92}$.

Desde los presupuestos más comunes a su época, explica que por naturaleza nadie tiene un derecho sobre las conductas de los otros, sino que todo derecho ha sido creado mediante un hecho humano, y lo aporta la sociedad, de modo que, puesta la sociedad, ya existe el imperio ${ }^{93}$. Pero se aparta de lo que era común entre aquellos juristas tan conservadores y explica que "Por naturaleza a ningún hombre le compete un poder sobre otro hombre, sino que todo imperium ha sido creado interviniendo algún hecho humano, y debe su origen a la sociedad, de forma que, puesta la sociedad está puesto el poder, y el imperium sólo puede provenir desde la sociedad" 94 . Esto lo hace de un modo francamente singular, porque la suya no es ni una ética de tránsito (desde la soledad a la sociedad civil) ni tampoco una ética de lín e a r e c t a que haya de desconocer por los propios términos de su definición, a los elementos extraños a los individuos y al Estado.

El poder civil -explica él- es un dominio compuesto por las clases distintas de derechos (de propiedad) entre los que destaca el dominium publicum o das Staatseigenthum". Entiende a la sociedad política como un hecho radical: "Posita respublica ponitur potestas civilis" ${ }^{6}$. Una realidad es la sujeción civil y las servitutes personales y cualquier otra sujeción ${ }^{97}$. El poder civil rectorio es una parte del poder que existe en la república, en el que el superior determina por su mayor poder lo que se debe hacer para la vida de la república ${ }^{98}$. Parece apuntar tímidamente

91 "Societatem herilem non esse a natura, sed facto humano interveniente introductam esse". Systema elementare, $\$ 822$.

92 "Quod III attinet ius ea definiendi quae influunt in subditorum existimationem civilem, huc pertinet jus superioris ordines civium (Stände), qui sunt clases civium, secundum quas certis praerogativis praealiis fruntur, quae per nativitatem in posteros propaguntur, et dignitates civiles (Würden)" [...] Systema elementare, \$1445.

93 "Natura nulli hominum competit imperium in alium, sed potius omne imperium interveniente facto humano est introductum, et originem debet societate ita, ut posita societate ponatur imperium, et non nisi ex societate imperium ortum trahere possit". Systema elementare, $\$ 419$.

94 "Natura nulli hominum competit imperium in alium, sed potius omne imperium interveniente facto humano est introductum, et originem debet societate ita, ut posita societate ponatur imperium, et non nisi ex societate imperium ortum trahere possit". Systema elementare, $\$ 419$.

95 "Potestas civilis definita est dominium, sunt quidem praecipua, ast tamen in se diversa, hominum jura, licet pars quaedam potestatis civilis sit dominium publicum (das Staatseigenthum), quod est dominium quod penes rempublicam est". DANIELIS, Systema elementare, $\$ 1255$.

96 "Posita respublica ponitur potestas civilis, eaque est, si Respublica sibi ipsi originem debet, originetur penes omnes cives simul sumtos, a quorum arbitrio dependent, an, quomodo et in quem eam transferre velint". Systema elementare, $\$ 1264$.

${ }_{97}$ "A subjectione civilis supra (\$ 1246) definita, differunt servitus personarum (\$ 820) et subjectio aut qualibet alia potestate praeter potestatem civilem; prout ex comparatione definitionum per se patet". Systema elementare, \$1267.

98 "Potestas civilis rectoria est pars potestatis civilis, vi cujus superior reipublicae determinat, quid salutis publicae causa fieri, vel non fieri, debeat”. Systema elementare, $\$ 1422$. 
hacia una cierta división de poderes, porque establece que uno es el poder civil y otro es el poder del magistrado 9 .

Nettelbladt reconoce la existencia de varios tipos de potestades en el interior de cada república, y con sus libros en la mano se puede hablar de p l u r a l is m o j u r í d i c o . Desde luego, distingue claramente entre el poder político y la 'libertad civil de los súbditos', que es el derecho que tienen ellos para determinarse sobre las conductas $\mathrm{c}$ i v il $\mathrm{m}$ e n t e indiferentes ${ }^{100}$. Si hubiera partido desde alguna versión del contrato social, como la voluntad humana es siempre igual a sí misma y sólo puede producir un solo poder de una misma naturaleza, los ciudadanos estarían sometidos al poder político menos aquellos derechos que ellos se hubieran reservado en la conclusión del pacto social. Pero, para él, el origen de la sociedad es un hecho radical indemostrable e inargumentable. Luego los poderes que existen son originarios por sí mismos, no derivados de un poder anterior o superior.

En su tónica de referirse a las diversas sociedades más que a los individuos, manifiesta que siempre que la sociedad es una sociedad lícita, los hombres, que viven en libertad natural, pueden constituir sociedades por su voluntad libre y pueden admitir o recusar a las que ya hay de forma igualmente libre ${ }^{101}$.

El poder del legislador siempre ha de contar con la libertad natural de los ciudadanos. Es por ello por lo que la potestad legislativa tiene límites naturales, que son: 1) las leyes no se pueden extender a aquellas acciones de los subditos a las que no alcanza la potestad civil, de modo que no se debe tratar lo que es civilmente indiferente; 2) las leyes civiles que son claramente contrarias a las leyes naturales no deben ser admitidas como leyes, sino que más bien las leyes civiles respecto a las leyes naturales deben estar redactadas de forma que añadan o detraigan algo a las leyes naturales de acuerdo con el bien de la república; 3) el legislador, al conceder privilegios, debe ser consciente que tiene este poder solo por la potestad legislativa que le ha sido encomendada ${ }^{102}$.

Pero no se conforma con lo que alguno de sus contemporáneos podría llamar los límites n a t u r a le s del poder político, siempre limitado por la objetividad de la ley natural y por las subjetividades de las libertades naturales de los hombres. Yendo más allá, quiere establecer las "leyes fundamentales de la república”, que es una expresión que comprende a las leyes que tratan sobre la policía de la sociedad

99 "Potestate civili etiam differt ius magistratus, quippe quod est pars potestatis civilis, ab eo qui potestatem civilem habet, concessa". Systema elementare, $\$ 1267$.

100 "Subiectioni civili opponitur 'libertas subditorum civilis', quae est jus subditorum actiones civiliter indifferentes pro suo arbitrio determinandi”. Systema elementare, $\$ 1272$.

101 "Quoties societas est licita societas, hominis in libertate naturali viventes pro lubitu eam constituere, et pro lubitu quem volunt admittere, vel recusare, possunt”. Systema elementare, $\$ 478$.

102 "Potestas legislatoris limites naturales sunt hi, quod superior 1) leges extendere nequeat ad eas subditorum actiones, ad quas vi libertatis subditorum civilis extendit nequit potestas civilis (\$ 1272) sic que non reformare debeat quos civiliter indifferentes est; 2) leges civiles legibus naturalibus plane contrarias, nec ferre, nec recipere, possit, sed potius leges civiles in respectu ad leges naturales tales esse debeant, quam iis, vel aliquid addunt, vel aliquid detrabunt, (\$ 140) salute reipublicae convenenter; 3) in privilegiando superior salutis publicae rationem habere debeat, ita, ut non nisi vi potestatis civilis eminentis ei hoc ius competat, et non nisi quoad leges quae a potestate legislatoria sibi competente dependent”. Systema elementare, \$1428. 
y de su poder civil ${ }^{103}$. Concretamente, establece que las leyes fundamentales de las repúblicas son de dos tipos, unas que se fundamentan en la naturaleza y esencia de la república en sí, y otras establecidas por la voluntad, por lo que a las primeras se las llama naturales y a las segundas positivas ${ }^{104}$.

Introduce una matización interesante porque podría pensarse que los límites $\mathrm{n}$ a t u r a l e s del poder están siempre operativos, mientras que los límites positivos pueden eliminarse según las fuerzas y las conveniencias. Concretamente, indica que las leyes fundamentales positivas obligan si la república es una sociedad igual por la fuerza del imperio contenido en el poder civil. Pero si la república es una sociedad desigual, obligan al modo de un pacto concluido entre el superior y los súbditos, por lo que a estas disposiciones sería preferible llamarlas pactos fundamentales que no leyes ${ }^{105}$. El derecho que posee la república para constituir leyes fundamentales es un derecho de la república que no se transfiere al Gobernante por el poder civil or d i n a r i o ${ }^{106}$. Entre estas leyes fundamentales positivas existen las que se llaman 'capitulaciones de los príncipes', que son pactos concluidos entre el pueblo y el príncipe y por los que se determina el alcance del poder civil, y hay que entender que estas capitulaciones obligan no por el poder del príncipe, sino al modo de un pacto ${ }^{107}$. También existen estas leyes en los regímenes aristocráticos, firmadas por una parte por los patricios y de otra parte por el pueblo ${ }^{108}$.

Igualmente existen estas leyes en las democracias, en donde hay que calificarlas de positivas, pero sabiendo que el pueblo que las crea y que las reforma de acuerdo con sus deseos, está sometido a ellas no por la fuerza del pacto ( $v i$ pacti), sino por la fuerza del imperio: sed vi imperii ${ }^{109}$. El poder civil -por seguir su terminología- como tal no depende de los que contratan: ya existe y los pactos solamente proporcionan su contenido. La república dispone de senadores, que son hombres tomados entre los ciudadanos, que dirigen la república y a los que

103 "Ad ea, quae de republica in se spectata in genere notanda, referri etiam potest doctrina de 'legibus fundamentalibus rerum publicarum', sub quo nomine in genereveniunt leges, quae versantur circa politiam reipublicae, eiusque potestatem civilem". Systema elementare, $\$ 1276$.

104 "Leges rerum publicarum fundamentales sunt dupliciis generis, dum vel tales sunt, quae in natura et essentia reipublicae fundare sunt, vel tales quae per voluntatem constitutae, quarum priores naturales, posteriores positivae leges funt”. Systema elementare, $\$ 1277$.

105 "Leges fundamentales positivae rerum publicarum obligant, si respublica est societas aequalis, vi imperii in potestate civili contenti: ast, si respublica est inaequalis societas, obligat per modum pacti inter superiorem et subditos cives initi; hincque potius pacta fundamentalia, quam leges, appellari debent". Systema elementare, $\$ 1278$.

106 "Ius leges fundamentales positivas constituendi, est ius reipublicae quod per potestatis civilis translationem in superiorem non transfertur. Hae leges enim reipublicae politiam et potestatem civilem concernunt". Systema elementare, $\$ 1279$.

107 "Tandem quoad leges fundamentales positivas regnorum addendum, in regni sobvenire speciem earum quae sub capitulationem principum nomine venit, et sunt pacta inter principem et populum seu iura excertentes ordines regni, por quae principis potestas civilis determinatur, sic que capitulationes non per modum imperii, sed per modum pacti obligant". Systema elementare, $\$ 1300$.

108 "In aristocratia dantur leges fundamentales positivae, quae vero consensu optimatium ab una, et populi ab altera parte, condi et mutari debent". Systema elementare, $\$ 1303$.

109 "In democratiis dantur quidem leges fundamentales positivae ast populus ipse eascondit et pro lubitu mutat, nec eae vi pacti, sed vi imperii, obligant”. Systema elementare, $\$ 1306$. 
corresponde la administración del poder civil ${ }^{110}$. El conjunto de los senadores o senado no es superior a la democracia, porque el senado no es una persona moral. Los senadores, considerados individualmente o en conjunto son súbditos de la democracia superior, que es el mismo pueblo ${ }^{111}$.

El derecho a constituir sociedades in $\mathrm{t}$ e $\mathrm{r} \mathrm{m}$ e $\mathrm{d}$ i a s es un derecho natural de los súbditos que quieran unirse para cualquier fin que no sea contrario al sometimiento civil; aunque la autorización del superior siempre es útil, sin embargo no es necesaria porque estas sociedades se crean por la fuerza de la libertad civil de los súbditos ${ }^{112}$. En esta misma línea de pensamiento expone que es condición para el propio regimiento de estas sociedades que su orden interno no sea contrario a la salud pública ${ }^{113}$.

Es el único jusnaturalista importante que habla de desposeer del trono al monarca que no se atenga a la justicia, y para esto crea un término nuevo: $\mathrm{d}$ e s e n t r o n i z a ción. Este derecho a privar del trono al monarca se puede poner en práctica si el gobernante transgrede manifiestamente los límites del poder que le compete, de forma que turbe el buen gobierno de la república de modo que su ejercicio pueda ser considerado tiránico ${ }^{114}$. Si sólo desconoce una parte de los derechos de los súbditos no cabe proceder a la desentronización, sino que hay que mostrar desobediencia y resistencia. Estos derechos se deducen ex jure defensionis ${ }^{115}$. Fueron declaraciones audaces en aquel momento.

\section{Johann GotTlob Heineccius (1681-1741)}

Posiblemente el j u s n a t u r a li s t a alemán más conocido del siglo XVIII fuera de los territorios alemanes. Sus numerosas ediciones foráneas dan fe de esto. Como era normal en este tipo de escritores, no se atiene a los límites que impone la ciencia del derecho sino que trata toda la filosofía práctica desde sus fundamentos más básicos.

110 "Senatores reipublicae in specie sic dicta dicuntur ii ex civibus, qui directorium reipublicae, quae democratia est, habent, quibusque simul potestatis civilis administratio". Systema elementare, $\$ 1369$.

111 "Senatorium collegium seu senatus non est superior democratiae, prout etiam senatus non est persona moralis in status naturali vivens. Sunt potius senatores tam qua singuli, quam coniunctim considerati, subditi superioris democratiae, qui est ipse populus". Systema elementare. $\$ 1371$.

112 "Cum societas privata sibi ipse originem debeat, ante omnia definiendum quatenus liceat subditus coire in societates privatas, ubi notandum licere iis ad quemlibet finem, qui talis est quoad subiectione civili non repugnet, obtinendum virem coniungere et in societate coite, ita ut, licet superioris confirmatio societatis semper utilis sit, ea tamen non sit necessaria. Vi libertatis subditorum civilis". Systema elementare, $\$ 1523$.

113 "Etsi ita quequae libet societas privata in republicae existens, possit vi potestatis privatae ei competentis ordinare suam politiam pro lubitu, quatenus politia saluti publica non est contraria". Systema elementare, $\$ 1528$.

114 "Desthronisisatio possiteum, si manifesto transgreditur potestatis sibi competentis limites, ita, ut totius regni salus publica turbetur". Systema elementare, $\$ 1402$.

115 "Non desthronanisitio, sed in priori casu inobedientia et resistentia tantum, in posteriori vero tantum subductio eorum, qui opprimuntur, locum habet [...] Ex jure defensionis deducenda sunt". Systema elementare, $\$ 1402$. 
Comienza haciendo una profesión de fe nominalista, algo que era de esperar en una persona que tiene tanto en común con Samuel Pufendorf. Entiende que no existen realidades en sí intrínsecas y antecedentes a lo que las leyes declaran que es justo $^{116}$. La norma de las acciones humanas es la voluntad de Dios, que es la fuente de todo derecho natural y de toda justicia ${ }^{117}$. Desde luego todo nominalismo ha de comenzar en la voluntad de un superior, y si hablamos de la ley natural, esta voluntad únicamente puede ser la de Dios. Pero, aunque sea difícil para expresarlo con palabras, proposicionalmente, el investigador intuye que está ante un problema similar al de Christian Wolff, quien alude a Dios continuamente y que fue expulsado de su Universidad acusado de ateísmo.

Su punto más elemental de partida es el común a este momento histórico: todos los hombres son iguales por naturaleza ${ }^{118}$. El estado natural (status naturalis) es un estado de igualdad (status aequalitatis) y nadie de los que vive en este estado es superior o inferior a otro, de forma que pueda existir alguna sujeción o alguna dignidad que los discrimine, ya que como dijo rectamente Ulpiano Quod ad jus naturale attinet, omnes homines aequales sunt ${ }^{119}$.

Una noción capital para entender la sociedad, es decir, su consistencia y sus fines, es la del do m i n i o, ya que cada uno dice que es suyo lo que está bajo su voluntad. Al filo de las ideas sobre la libertad podríamos preguntarnos si el dominio sobre los propios actos es la manifestación primera o más importante de este s e r d e u n o (suum proprium), al que él también llama jus o facultad, de forma que pueda excluir a los otros del uso de la $\operatorname{cosa}^{120}$. No parece ser así porque él reconoce la licitud de la esclavitud en la sociedad heril ${ }^{121}$. Esto plantea una cuestión interesante: todos estos autores sólo tratan la esclavitud al ocuparse de la sociedad heril o familiar, y poco importa que consultemos también a Daries y a Nettelbladt, que todos dicen lo mismo: les resultaba evidente que había de haber siervos en la casa. Pero nunca hablan de esta servidumbre cuando tratan el resto de las instituciones sociales. Sería cuestión de indagar en los tratados protestantes de moral de aquella época para saber si admitían esclavos en el trabajo del campo o de las fábricas.

Las sociedades civiles se han originado por los excesos, en el estado natural, de

116 "Falsum tamen est, actionem illam intrinsecus et antecedenter ad legem justum esse". Elementa juris naturae et gentium. Commoda auditoribus methodo adornata. Cum notis sacerdotii Andreae Cantoris Amato (Neapoli, 1829 [primera edición de 1737]), L. I, \$70.

117 "Voluntas vero Dei sit normam actionum humanarum liberarum, adeoque fons juris naturae ac justitiae". Elementa juris naturae et gentium, L. I, $\$ 78$.

118 "Facile patet, ad amorem justitiae homines cogi posse, non autem ad amorem humanitatis ac beneficentiae”. HEINECCIUS, Elementa juris naturae et gentium, L. I, \$84.

119 "Status naturalis sit status aequalitatis, ac proinde eorum, qui in illo status vivunt, nemo altero vel superior sit, vel inferior est, quod subsequi inde necesse est, nec subjectioni, immo nec ulli dignitatum discrimini in illo locus sit, adeoque recte recte scripserit Ulpianus: 'Quod ad jus naturale attinet, omnes hominesaequales sunt”. Elementa juris naturae et gentium, L. $2, \$ 5$.

120 "Suum propium quisque vocat, quod in dominio suo est. Dominium vero vocamus jus, seu facultatem, alios usu rei alicujus excludendi". Elementa juris naturae et gentium, L. I, $\$ 231$.

121 "De Officiis in societate herili observandis". Admite la esclavitud. Elementa juris naturae et gentium, L. 2, Cap. 4. 
hombres malos que quieren subyugar a los otros y desposeerlos de sus propiedades. Fue lógico que se unieran varios patresfamilias para estar a salvo de estas personas. Así llegaron a formar sociedades grandes, con los gobiernos delegados en pocas personas, por lo que estas sociedades hubieron de ser necesariamente desiguales y rectorias $^{122}$, de modo que llegaron a constituir dos tipos de sociedades, unas para reprimir a los ímprobos en el interior y otras para la defensa exterior de la ciudad ${ }^{123}$.

Las sociedades se crean mediante contratos ${ }^{124}$. Hay que entender por ciudad el consenso de dos o más para alcanzar un fin, y el derecho a poseer los medios que son necesarios para alcanzar ese fin ${ }^{125}$. Éstas son leyes que se derivan directamente desde la ley natural, porque las leyes civiles (recordemos la distinción romana entre derecho natural, derecho de gentes y derecho civil, que Heineccius la tiene presente) son preceptos generales dictados por el supremo gobernante sobre actos moralmente indiferentes que tienden a conseguir la mayor utilidad y gloria para la república ${ }^{126}$. No explica cuáles son los actos indiferentes; parece, del conjunto, que se refiere a las acciones no contenidas en las leges fundamentales. Parece más adherido a la realidad cuando explica que, aunque el monarca dispone las cosas según su arbitrio, no debe normar sino lo que requiere el fin de la ciudad, que es la seguridad de los ciudadanos ${ }^{127}$. Las leyes civiles no obligan en conciencia a su cumplimiento $^{128}$; simplemente se les aplican lo previsto en ellas a quienes realizan las conductas previstas en ellas, mediante una imputatio. Seculariza, del mismo modo que Thomasius el creador de la Zurechnung o imputatio en el sentido que usamos ahora este término,

En las ciudades los hombres son socios, y todos dependen igualmente del fin común, por lo que cabe decir que tienen el mismo fin ${ }^{129}$. No caben las irracionalidades, porque así como hay una sola voluntad debemos entender que existe

122 "Quum enim in status naturali omnes sintaequales et liberrimi, et ea tamen sinthominum improborum indoles, ut aliis dominari, eosque subjugum mittere, rebusque spoliare, mirifice cupiant: fieri profecto non potuit, quin plures patresfamilias ejusdem ingenii vires unirent, aliosque sibi obnoxios redderent. Quumque magna societas non posse non esse, inaequalis et rectoria: consequens est, ut illa latronum turba sibi ducem elegerit, certamque ei formulam imperii praescripserit, atque inde nata sit societas civilis vel Respublica". Elementa juris naturae et gentium. L. 2, cap. $6 \$ 103$.

123 . Elementa juris naturae et gentium, L. 2, \$105.

124 "Quum ergo civitas consistat in consociatione tantae hominum multitudinis, cujus vires junctae non sint impares vicinorum potentiae, sine consensu non intelligatur societas: consequens est, ut et civitates vel respublicae, interveniente pacto constituantur". Elementa juris naturae et gentium, L. 2, \$ 108.

125 "Et hic quidem per societatem intelligimus consensum duorum pluriumve in eumdem finem, eademque media, quae ad finem illud obtinenedum sunt necessaria". Elementa juris naturae et gentium, L. 2, \$2.

126 "Facile patet, leges civiles esse praecepta generalia summi imperantis de actionibus externis indifferentibus, ad decum utilitatem que reipublicae componendis". Elementa juris naturae et gentium, L. 2, \$ 150 .

127 "Quamvis vero omnia suo arbitrio agat monarca: non tamen agere aliud debet, quam quod finis civitatis, puta securitas civium, requirit". Elementa juris naturae et gentium, L. 2, \$121.

128 Elementa juris naturae et gentium, L. 2, \$152.

129 Ibíd., L. 2, \$ 24. 
una misma inteligencia en la ciudad o república ${ }^{130}$. Ya que hay asenso en el fin a alcanzar, los medios para alcanzar ese fin han de ser entendidos como necesarios. Como las ocupaciones están en las manos de otros es necesario someterse la voluntad ajena, concretamente, a la del Gobernante ${ }^{131}$. Por lo general, Heineccius, con su insistencia en la unidad de la voluntad en las sociedades inaquales y rectorías, así como en el empeño que pone en mostrar la necesidad de este tipo de sociedades, parece en buena medida un teórico de la monarquía.

Muestra una preocupación continua por explicar que son lícitas nuestras ciudades, de grandes proporciones y por ello necesitadas de una forma de gobierno que sea desigual y rectoria. Desigual, en este contexto, quiere decir que unos ocupan cargos públicos y otros no, lo que parece oponerse a las exigencias de la democracia. Sucede que cuanto mayor es la sociedad, más difícil es reunir a sus miembros para lograr un consenso ${ }^{132}$. Él explica que hay tres formas de gobierno de acuerdo con las posibilidades de la voluntad: la monarquía, la democracia y la aristocracia ${ }^{133}$. Si existe una democracia y el pueblo tiene que reunirse frecuentemente, la praxis política se corromperá ${ }^{134}$.

Pero en la monarquía el Rey actúa según su arbitrio, y aunque haya personas más prudentes y con méritos, las opiniones de estas personas no constituyen sentencias sino consejos ${ }^{135}$.

La civitas se origina mediante el acuerdo de varios patresfamilias que componen el populus. En su inicio, la forma de gobierno de la república exige el consentimiento de todo el pueblo, de modo que las personas que gobiernan sean elegidas mediante el pueblo mismo, y estas personas están sometidas a ciertas leyes fundamentales; porque es evidente que en la república nadie adquiere para sí el imperio sin la voluntad del pueblo y según las leyes fundamentales de la república ${ }^{136}$. El Gobierno ha de tener una forma y el pueblo tiene perfecto poder para elegir a las personas que lo han de gobernar de acuerdo con 'cierta fórmula del imperio' dictadas por un decreto superior, y a las que llamamos correctamente leyes fundamentales, que obligan tanto a los gobernantes como el pueblo"137.

130 "Ceterum, quem ad modum omnium societatum una voluntas, unusque intellectus concipit debet: ita idem dicendum est de civitate vel respublica, ita constituta". Elementa juris naturae et gentium, L. 2, \$114.

131 Elementa juris naturae et gentium, L. 2, \$ 114.

132 "Societates aequales et inaequales (rectorias). Res ipsa autem et ingenii humani indole unum quemque convincent, quo maior est societas, eo minus fieri posse, ut tanta sociorum multitudo media necessaria communi consensu et sufragio inveniat, adeoque, quo maior est societas, eo magis eam esse debere rectoria et inaequalem”. Elementa juris naturae et gentium, L. 2, $\$ 18$.

133 Elementa juris naturae et gentium, L. 2, \$115.

134 Ibíd., L. 2. \$123.

135 "Ex eodem patet, monarcham omnia ageresuo arbitrio, et quamvis prudentiores merito adhibeat in consilium, eorum tamen suffragia non sententias, sed consilia esse". Elementa juris naturae et gentium, L. 2, \$120.

136 "Ceterum, quia et forma reipublicae initio totius populi consensu constitutae, et ipsae personae imperantes ab eodem populo electae, iis quecertae leges fundamentales praescriptae sunt: facile patet, neminem adquiere sibi imperium posse in republicae, nisi volente populo et secundum fundamentales reipublicae leges". Elementa juris naturae et gentium, L. 2, \$ 137.

137 "Denique, ubi de reipublicae forma convenit, nihil populo deest ad perfectam rempublicam, 
¿Quién dicta estas leges fundamentales? No pueden consistir en una realidad racional, antecedente a las acciones humanas, porque Heineccius exhibe un nominalismo estricto y desecha expresamente la posibilidad de deberes que no ve ng a n c r e a d o s impuestos por las leyes. Tampoco las presenta como unos laws of reason, como hizo Hobbes. Alude a ellas y ellas le sirven para componer su figura geométrica, que de otro modo quedaría incompleta. Pero, a pesar de que procede como un autor muy del siglo XVIII, que comienza explicando desde lo más elemental, su versión de las leges fundamentales hace que estas reglas permanezcan como un factum sin explicación ulterior.

\section{Christian WolfF (1679-1754)}

Uno de los personajes más conocidos del Iluminismo fue Christian Wolff. No es fácil exponer su doctrina porque es un autor que pretende ocultar casi tanto como afirma, con una actitud claramente calculada. Salta a la vista su condición de filósofo, que le lleva a redactar con especial claridad y lógica. Como se echó sobre sus hombros la tarea de componer un tratado íntegro de derecho natural, redactó ocho volúmenes a razón de un volumen por año. El último de ellos es el dedicado a la teoría política.

Como era corriente en el Iluminismo, mantiene que el pueblo es el titular originario del poder político, por lo que es libre para transmitirlo a quien quiera ${ }^{138}$. En cierto tono declamatorio, declara que el Rector Civitatis ha de buscar el bien de la república ${ }^{139}$, y el gobernante que hace cosas buenas porque fomenta el bien público, es bueno, y será un mal gobernante si realiza conductas que se oponen al bien público ${ }^{140}$. A partir de un cierto momento de este capítulo comienza el tratamiento del régimen democrático ${ }^{141}$. Esto último era lo corriente en los autores ilustrados, que tratan de la democracia ex hypothesi, sabiendo -o creyendo saber- que era una realidad muy ajena a ellos.

El imperium que transmite el pueblo al Gobernante puede ser limitado o absoluto $^{142}$. El poder absoluto no es malo en sí mismo: es malo su abuso ${ }^{143}$. Pero aunque contempla estas dos posibilidades, lo cierto es que él sólo tiene ante su vista el imperium absolutum, y explica que si "El imperio es transferido al Gobernante, tal como existe en el pueblo, el Gobernante tiene un poder pleno, absoluto y sumo, de forma que tiene un derecho de propiedad sobre porque está en su

quam ut eam easque personas, quas sibi imperare velit, eligat, et ei iisve, certam imperii formulam, jam tum superiore decreto expressam, praescribat, quae formula tunc recte leges fundamentales nomine venit, Quum et ea, quae pactiscaventur, passim leges adpellentur, ac proinde imperantes sive unum, sive plures, non minus quam cives obligant [...]”. Elementa juris naturae et gentium. L. $2, \$ 111$.

138 WolfF, Pars octava, sive ultima de Imperio publico seu jure civitatis in qua omne jus publicum universale demonstrantur et verioris politicae inconcussa fundamentum ponuntur (Halae Magdeburgicae, 1748), cap. I, $\$ 57$.

139 Pars octava.., cap. I, $\$ 84$.

140 Ibíd., cap. I, $\$ 85$.

141 Ibíd., cap. I, \$\$ 131 y ss.

142 Ibíd., cap. I, 88.

143 Ibíd., cap. I, $\$ 89$. 
patrimonio"144. Habría que concluir que si el poder normal es aquel que tiene el pueblo sobre sí mismo, lo normal es el régimen absoluto en el que el Rector detenta el poder jure proprietatis ${ }^{145}$. En algunas ocasiones alude al dominium eminens que corresponde al gobernante si es que lo exige la salus publica; pero lo cierto es que, tal como expone el resto de su pensamiento, el gobernante dispone por lo general de este dominio, sin necesidad de que se den circunstancias especiales ${ }^{146}$, ya que al Rector le corresponde tal dominium siempre que se trate de acciones que promuevan el bien público ${ }^{147}$.

El grado sumo del imperio no siempre, necesariamente, corresponde al pueblo, y por ello el pueblo no siempre tiene algún derecho sobre lo que hace el Gobernante, ni por ello un derecho de coaccionar y castigar al Rey en un imperio absoluto $^{148}$. "En consecuencia el imperio no pudo haber sido transferido bajo esta ley, que el pueblo ha de obedecer al gobierno recto, pero que le es ilícito resistir y coaccionar al mal gobernante" ${ }^{149}$. De forma consecuente trata los pactos generales. Bajo esta expresión entendían entonces lo que ahora llamamos leyes fundamentales. Declara que "Los pactos generales que regulan el oficio del buen Rector, sólo limitan el imperio absoluto de forma mínima [...] y por estos pactos apenas se determina la forma de administrar el poder ${ }^{150}$. Había sido más explícito poco antes cuando indicó que los pactos generales [...] no transmiten ningún derecho al pueblo sobre los actos del gobernante"151. En otras palabras, Wolff, siempre viviendo bajo la sombra del poder del Káiser, denegó cualquier derecho de resistencia que le pudiera corresponder al pueblo.

\section{IMMANUEL KANT (1724-1804)}

Otto von Gierke suele remitirse a Kant como la coronación de las doctrinas contractualistas que fueron propias de la Escuela del Derecho natural moderno ${ }^{152}$. Pero lo cierto es que Immanuel Kant estuvo asustado ante la Revolución. La Rechtslehre kantiana, que apareció en 1796 como segunda parte de la Metafísica de las costumbres, es un tratado de Derecho natural fiel a los principios básicos de

\footnotetext{
144 WOLFF, "Si imperium in Rectoren civitatis transfertur, quale est in populo; imperium habet plenum, absolutum, summum idque jure proprietatis, seu in patrimonio”. Pars octava.., cap. I, $\$ 91$.

145 Pars octava.., cap. I, $\$ 93$.

146 WolfF, "Quamobrem cum jus certo modo disponendi de rebus civium, si salus publica exigat, dominium eminens sit, jus autem disponendi de persona ipsorum in simili casu potestas eminens; qui in civitatem coëunt, in dominium eminens; et potestatem eminentem consentiumt". Pars octava.., cap. I, $\$ 118$.

147 Pars octava.., cap. I, $\$ 117$

148 Ibíd., cap. I, $\$ 59$.

149 WolfF, Pars octava.., cap. I, "Quamobrem imperium nequit transferri ea lege, ut populus universus recte imperanti parere debeat, male autem imperanti resistere eunque coërcere possit". $\$ 82$

150 Pars octava.., cap. I, $\$ 126$.

151 WolfF, "Pacta generalia, quae saltem exprimunt officium boni Rectoris, cum Rectore civitatis in susceptione imperii inita, nullum tribuunt jus populo in actu imperantis". Pars octava..,cap. I, $\$ 126$.

152 Vid. Johannes Althusius und die Entwicklung der naturrechtlichenStaatstheorien, reproducción de Scientia Verlag, Aalen, 1981, de la $7^{\text {a }}$ edición alemana, p. 122, por ejemplo.
} 
esta Escuela. Ciertamente, Kant no fue original porque antes de que él redactara su Rechtslehre ya habían aparecido varios tratados de filosofía jurídica escritos al filo de su filosofía c rít i c a y él los sigue.

En efecto, Kant enseñó Derecho natural, en calidad de Privatdozent, durante más de veinte años, explicando el Jus Naturae in usu mauditorium de Gottfredus Achenwall; en consecuencia, su formación en la teoría jurídica vino de la mano de un autor muy representativo del pensamiento dominante en la Modernidad. A grandes rasgos, y de forma muy imprecisa, podría decir que la aportación más importante de Kant, aparte de rechazar el eudemonismo como criterio supremo de la filosofía práctica, y proponer en su lugar un concepto de obligatio mucho más depurado, que ya había explicado extensamente, treinta años antes, B. Chr. Fr. Schott ${ }^{153}$, fue la labor de depuración de los conceptos jurídicos fundamentales de la Modernidad que, tras la reelaboración que sufren en sus manos y en las del medio centenar de $\mathrm{k}$ a n ti a n o s que escriben en el cambio de siglos, resultaron más afilados y precisos y -todo hay que decirlo- alejados en ocasiones de su contenido original ${ }^{154}$.

Pero, aparte del carácter epigonal de la filosofía jurídica de Kant, por paradójico que parezca, antes de que fuera publicada la segunda parte de la Metafísica de las costumbres, ya habían aparecido casi una veintena de obras que trataban el Naturrecht-que ya comenzó a llamarse Metaphysik des Rechts o Reine Rechtslehredesde el ángulo de la filosofía crítica kantiana. Son tratados semi-kantianos, por ejemplo, los de Höpfner, Naturrecht des einzelnen Menschen, der Gesellschaften und der Völker (2a edición de 1783), Adolph Dietrich Weber, Systematische Entwickelung der Lehre von der natürlichen Verbindlichkeit (1784), Johann August Schlettwein, Die Rechte der Menschheitoder der einzigewahre Grundaller Gesetze, Ordnungen und Verfassungen (1784), Johann August Eberhard, Über die Freyheit der Bürger und die Principien der Regierungformen (1784), Gottlieb Hufeland, Versuch über den Grundsatz des Naturrechts (1785), o el de Johann Georg Heinrich Feder, Grundlehrenzur Kenntniss des natürlichen Willens und der natürlichen Gesetze des Rechtsverhalten (1789).

El año clave en la formación de la filosofía jurídica c r í t i c a es 1792, cuando aparece la primera edición del Handbuch der Rechtsphilosophie de Theodor Schmalz. Esta pequeña obra de Schmalz, que constituye el primer tratado de filosofía jurídica kantiana, desencadenó definitivamente la formación de la Escuela kantiana, Die Kantianer, y, en poco tiempo, aparecen las obras de J. Chr. G. Schaumann, Wissenschaftliches Naturrecht (1792), Johann Heinrich Abicht, Neues Systema aus der Menschheit entwickelten Naturrecht (1792), Johann Christoph Hoffbauer, Naturrecht aus dem Begriffes des Rechts entwickelt (1793), Karl Heinrich Heydenreich, System des Naturrechts nach kritischen Prinzipien (1794), Wilhelm Gottlieb Tafinger, Lehrsätze des Naturrechts (1794), la del ya citado Schaumann (1795), C. S. Zachariä, Grundlinien einer wissenschaftlichen juritischen Encyclopädie (1795), Carl Christian Schmid, Grundriss des Naturrechts für Vorlesungen

153 Schотт, Dissertationes juris naturalis (Erlangae, 1784). La Dissertatio III, titulada “De notione obligationis", fue presentada en la Universidad de Tubinga en el mes de octubre de 1759.

154 Estudié la escuela kantiana en La Cabeza de Jano (Universidad de Cádiz, 1989). 
(1795), etc. Varios de estos autores publican en este período de 1792-96 algunas obras jurídicas distintas en las que explican, y crean al mismo tiempo, la filosofía jurídica kantiana desde diferentes ángulos.

De este modo, cuando Immanuel Kant se decide a redactar su tratado propiamente jurídico, disponía ya de bastantes estudios que explicitaban la teoría jusnaturalista desde la óptica de su filosofía crítica. De hecho, Kant sigue, por lo general, muy estrechamente lo ya expuesto por los filósofos $\mathrm{k}$ a n t i a n o s -valga la expresión- especialmente el tratado de Schmalz. Teniendo en cuenta estos datos, podemos comprender que la teoría jurídica kantiana fue una obra colectiva. Si atendemos a las recensiones que aparecieron a raíz de la publicación de la Rechtslehre personal de Kant, esta obra tardía del maestro defraudó, ya que no aportaba nada substancialmente nuevo y, al mismo tiempo, escandalizó por sus opiniones acerca de negación total y radical del Jus necessitatis y del derecho de resistencia.

En lo que hace más concretamente a nuestro tema, Kant escribía que "El origen del poder supremo es inescrutable -bajo el punto de vista práctico- para el pueblo que está sometido a él, es decir, que el súbdito no debe razonar prácticamente sobre este origen [...] (el pueblo) no puede ni debe juzgar de otra manera que como agrada al poder soberano existente (summus imperans).

Que haya tenido lugar un verdadero contrato primitivo de sumisión civil (pactum subjectionis civilis) a este poder, o que el poder le haya precedido y la ley no haya venido sino más tarde, todo esto, para el pueblo que ya está sometido a la ley civil, son disputas vanas, y peligrosas para el Estado"155.

En consecuencia -prosigue Kant- "Si el súbdito que investiga hoy este origen quisiese resistir a la autoridad existente, debería ser castigado con toda razón, expulsado o desterrado como proscrito, ex lex, en nombre de las leyes de esta autoridad"156. La razón de esta actitud reside en que "Una ley es tan santa e inviolable que es un crimen ponerla en duda en la práctica y, por consiguiente, impedir su efecto un solo instante, y es concebida de tal modo que no debe ser mirada como procedente de los hombres, sino de algún legislador muy grande, muy íntegro, muy santo; y tal es el sentido de la máxima Toda autoridad viene de Dios; máxima que enuncia no ya un principio histórico de la constitución civil, sino una idea como principio de la razón práctica, a saber: que es necesario obedecer al poder legislativo actual, sea cual fuere su origen"157.

"De ahí el principio: el soberano no tiene hacia el súbdito más que derechos, no deberes (de coacción); por lo demás, si el órgano del soberano, el gobernante, obrase contra las leyes, por ejemplo, en materia de impuestos, de quintas, etc., contra la ley de la igualdad en la distribución de las cargas públicas, el súbdito po-

155 Principios metafísicos de la doctrina del Derecho (trad. de A. Córdova, UNAM, México, 1978), p. 149. Kant era un anciano cuando publicó esta segunda parte de su Metafísica de las costumbres y pocos años después fue desposeído de su cátedra por debilidad senil. Esto hace que la lectura de esta obra en su lengua original sea demasiado onerosa, y he preferido servirme del trabajo de los que nos han precedido.

156 Principios, cit. (n. 155), pp. 149-150.

157 Ibíd., p. 150. 
dría oponer quejas (gravamina) a esta injusticia, pero jamás ninguna resistencia"158. La razón de esta opinión tan radical es que "No puede haber en la constitución ningún artículo que conceda a un poder en el Estado el derecho de oponerse al Soberano en el caso de que éste violase la constitución" ${ }^{159}$.

"El soberano -prosigue Kant- obra despóticamente por medio de sus ministros, y el prestigio de dejar al pueblo representar por sus diputados el poder restrictivo (puesto que el pueblo no tiene propiamente más que el poder legislativo) no puede disimular el despotismo de tal manera que no sea visible por los medios que emplean sus ministros"160 "No hay, pues, contra el poder legislativo, soberano de la ciudad, ninguna resistencia legítima de parte del pueblo; porque un estado jurídico no es posible más que por la sumisión a la voluntad universal legislativa; ningún derecho de sedición (seditio), menos aún de rebelión (rebellio), pertenecen a todos contra él como persona singular o individual bajo pretexto de que abusa de su poder" ${ }^{161}$. "La violencia ejercida en su persona, por consiguiente el atentado a la vida del príncipe (monarchomachismus sub specie tyranicidii) no está permitido. La más ligera tentativa de este género es un delito de alta traición, y un traidor de esta naturaleza debe ser castigado con la pena de muerte"162.

"La razón del deber -prosigue Kant- en que está el pueblo de soportar hasta el abuso del poder soberano declarado insoportable, consiste en que la sublevación contra el poder legislativo soberano debe siempre ser considerada como contraria a la ley, y aun subversiva de toda constitución legal. Para que la sublevación fuese permitida, sería preciso que hubiera una ley pública que la autorizase. Pero, entonces, la legislación suprema contendría en sí una disposición según la cual no sería soberana, y el pueblo, como súbdito, en un solo y mismo juicio se constituiría en soberano de aquél a quien está sometido, lo que es contradictorio"163.

Es preciso obedecer siempre y en todo caso al poder constituido, sea éste cual fuere. Si se produce una revolución y "Se establece una constitución nueva, la injusticia de este principio y fin de esta constitución no puede dispensar a nadie de la obligación de someterse al nuevo orden de cosas como buenos ciudadanos, y no pueden dejar de obedecer a la autoridad soberana que está entonces en el poder" ${ }^{164}$.

Planteadas así las cosas, es comprensible que Feuerbach escribiera en su Anti-Hobbes de 1798: “¿En qué medida este Anti-Hobbes no debiera ser un Anti-Kant?" 165 . La observación, entre otras, más precisa es, quizás, la que hizo Schmidt: "Según el profesor Kant no es lícito en ningún caso ejercer fuerza contra el soberano legislador [...] Pero según el profesor Kant solamente puede ser adecuada al Derecho de una forma de gobierno democrática [...] de lo que se

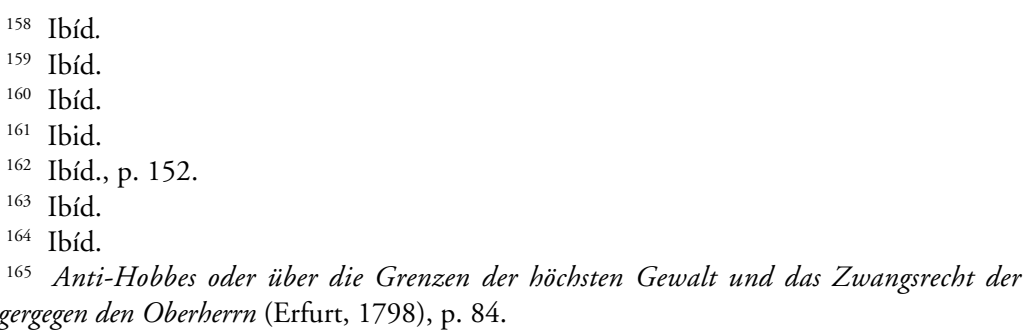
Bürgergegen den Oberherrn (Erfurt, 1798), p. 84. 
deduce que en una democracia no se puede ejercer ninguna violencia -justificable jurídicamente- contra la voluntad popular o la soberanía popular [...] Pero no veo cómo es posible aplicar el principio del señor Kant a una monarquía. De la doctrina kantiana se desprende más bien lo contrario, a saber, que una constitución (política) que no asegure mediante leyes generales la libertad o los componentes esenciales de ella [...] es completamente contraria al derecho, no puede subsistir, $\mathrm{y}$ en todo momento el pueblo puede oponerle resistencia" ${ }^{166}$.

\section{BiBLIOGRAFÍA}

ACHenWall, J. G., Iuris naturalis pars posterior complectens jus familiae, jus publicum et jus gentium in usum auditorium (8 ${ }^{\mathrm{a}}$ ed., Göttingen, 1781).

Carpintero Benítez, Francisco, La Cabeza de Jano (Universidad de Cádiz, 1989).

- Deber y fuerza: la Modernidad y el tema del deber jurídico, en Obligatoriedad y derecho. XII Jornadas de Filosofía Jurídica y Social (Universidad de Oviedo, 1991), pp. 151-182.

- El desarrollo de la facultad individual en la Escolástica, en ÉL MISMO (ed.), El derecho subjetivo en su historia (Universidad de Cádiz, 2003), pp. 35-288.

- Imputatio, en Rivista Internazionale di Filosofia del Diritto, 81 (2004) pp. 25-78.

- La Modernidad jurídica y los católicos, en Anuario de Filosofía del Derecho, 5 (1988) pp. 383-412.

DARIES, J. G., Institutiones jurisprudentiae universalis in quibus omnia juris naturae, socialis et gentium explanantur ( 6 a ed., Jenae, 1764).

- Systema elementare universae jurisprudentiae naturalis in usum praelectionum academicarum adornatum ( $3^{\text {a }}$ ed., Halae Magdeburgicae, 1767), $\$ \$ 22$ y 23.

Feuerbach, P. J. A., Anti-Hobbes oder über die Grenzen der höchsten Gewalt und das Zwangsrecht der Bürger gegen den Oberherrn (Erfurt, 1798).

GIERKE, Otto v., Johannes Althusjus und die Entwicklung der naturrechtlichen Staatstheorien, (reproducción de Scientia Verlag, Aalen, 1981, de la 7a edición alemana).

Gundling. N. H., Erläuterung über Samuelis Pufendorfii zwey Bücher De Officio hominis et civis (Hamburg, 1744).

GuZmán Brito, Alejandro, Historia de la denominación del derecho-facultad como 'subjetivo', en Revista de Estudios Histórico Jurídicos, 25 (2003) pp. 407-443.

Heineccjus, J. G. Elementa juris naturae et gentium. Commoda auditoribus methodo adornata. Cum notis sacerdotii Andreae Cantoris Amato, (1737, Neapoli, 1829), L. $2, \$ 129$.

HоввES, Th., Leviathan, or the matter, form and power of a Commonwealth ecclesiastical and civil (London, 1839).

166 "Nach Professor Kant darf gegen das gesetzgebende Staatsoberhaupt in keinem Falle Gewaltgebrauch twerden [...] Nach Herr Professor Kant kann nun eine Gegen den allgemeinen Willen, oder die Volkssouverainitätlässtsich nun freilich in der Demokratie kein Rechtszwangmöglichdenken [...] Aber ich sehe nicht ein, wie man sich nach dem Princip des Herrn Professors Kant eine Monarchie gültig unterwerfen können, dem Kantischen Principfliesst vielmehr das Gegenteil, das snämlich eine Erfassung, durch die oder der wesensliche Bestandtheil derselben nicht nach einemall gemeinen Gesetze versichert ganz und gar rechtswidrigsey, unmöglich bestehen könne, und somit alle Augenblick wider demVolke auf gehoben werden möge". Versuch einer Grunlage des Naturrechts (Ausburg, 1801), \$\$ 48-52. 
Kant, I., Principios metafísicos de la doctrina del Derecho (trad. de A. Córdova, UNAM, México, 1978).

Nettelbladt, D., Systema elementare universae jurisprudentiae naturalis in usum praelectionum academicarum adornatum ( $3^{\mathrm{a}}$ ed., Halae Magdeburgicae, 1767).

SCHMIDT, notax, Versuch einer Grundlage des Naturrechts, (Ausburg, 1801).

Sснотт, B. Chr. Fr., Dissertationes juris naturalis (Erlangae, 1784).

VATTEL, Emerico de, Iuris naturalis pars posterior complectens jus familiae, jus publicum et jus gentium in usum auditorium (8a ed., Göttingen, 1781).

WolfF, Christian, Pars octava, sive ultima de Imperio publico seu jure civitatis in qua omne jus publicum universale demonstrantur et verioris politicae inconcussa fundamentum ponuntur (Halae Magdeburgicae, 1748). 
